\title{
Teología aymara. Implicaciones para otras teologías
}

\section{Diego Irarrazaval, \\ Chucuito, Perú.}

La reflexión indigena, cosmo-centrada, ¿qué aporta a la tcología contemporánea hecha con la mentalidad de sujetos históricos? Una rellexión particularizada, aunque afectada por acontecimientos locales y transnacionales, ¿cómo interactúa con otros modos de pensar y cómo revoluciona a los no-indigenas?

Nos conmocionan fabulosas transformaciones en todo el planeta y en cada ámbito dc la existencia huriana. La mundialización de paulas cconómicas y dc pautas de diversión, la revolución de la informática, la ingeniería genélica, las reivindicaciones ecológicas y otros cambios —aunque inculcados por las élites- afectan en mayor o menor grado a Loda la humanidad. Tenemos, además, verdaderos tertemotos sociales: multitudinaria migración a ciudades y forja de identidades populares nuevas, infinita hambre y enfermedad, amplio acceso al sistema educacional, multifacético protagonismo popular, nítida imupción de la mujer, entrecruzamiento de violencias y de esfuerzos por sobrevivir, un generalizado afán por "progresar", y en medio de estos terremolos, el ciudadano anómino va reconstruyendo su existencia. A esto se suman otras complejidades: caídas de regímenes e ideologías-autoritarias, y, por otro lado, afianzamiento del totalitarismo del mercado, acentuación del neo-liberalismo, auge de fundamentalismos (en lo político, en lo religioso, en lo parasicológico, en lo deportivo, en el nacionalismo...), fracaso de proyectos de desmilitarización mundial, exacerbación hedonista, y - en medio de la secularización - incontables sincretismos religiosos y movimicntos de espiritualidad.

Con este transfondo, se hacen ensayos en las ciencias, en el "sentido común", en la filosofia, en la teología (como la aymara). A todos ellos les caracteriza ser ensayos - cada uno en su terreno- de carácter inaugural, ya que el acontecer humano va esbozando lo que podemos llamar nuevas líneas básicas. Por todas partes brolan en nuestra época evidencias que maduran, y mientras se 
cierran unas trayectorias se abren otras nuevas. En este sentido estamos en un momento inaugural y nos preocupan las dichas líneas básicas.

Pues bien, en medio de lodo esto ¿cuál es el perfil de la teologia? Ante las fascinaciones contemporáneas, como son la subjetividad, el progreso cientílico y técnico, el mercado planetario, el placer instantáneo y otros variados fenómenos, una comunidad creyente se siente asediada por ídolos y se siente también llamada a razonar su esperanza. La teología de "los de abajo" afirma posturas alternativas a dichos absolutos. De esta forma no tiene un perfil anodino, sino que entra en confrontaciones, [ormula con generosidad y calidad simbólica perspecuvas desde la periferia de la historia. Estas perspectivas son también compartidas generosamente con quienes están abiertos a símbolos que entrañan alternativas. Dado tantísimo obstáculo a la sobrevivencia, se cree en milagros. Y en medio de interminables y agobiantes dolores, se tiene esperanza en quien es roca de salvación.

En concreto, hacen teología aymara quienes tienen identidad, organización, pensamiento y espiritualidad aymara'. Reflexionan una realidad sagrada y la fe común. La piensan como población agobiada, cuya esperanza está pucsta en mediaciones salvíficas. $Y$ esta cosmovisión es conjugada con el itinerario cristiano de la salvación del mal. Esta teología puede, pues, llamarse teología aymara cristiana. (Existe también una teología en tomo al ceremonial, liderazgo y saber aymara, con cscaso o ningún componente cristiano, que puede ser llamado "pensamiento rcligioso aymara", rica temática que no incluyo en este artículo.)

En la medida en que personas aymaras se autodesignan y son católicas, puede haber una comprensión de fe en la Iglesia y de la Iglesia. Ello, además, impacta a ouros modos de pensamicnto. En este sentido escribo eslas páginas. Como no-aymara y como católico, presente en este pueblo, veo que la teología hecha por esta población indígena se conecta con necesidades de otras tcologías. Mi punto de partida es la productividad aymara, dentro del afán generalizado por las ya mencionadas "líneas básicas".

Vuelvo a la denominación. ¿Es acertado hablar de aymara-cristiano? Si la definición se toma desde lo aulóctono, puede hablarse de una pachasophia, porque pacha (término quechua-aymara) significa espacio y tiempo, es decir, lineamientos de lo existente; y sophia puede abarcar conocimiento, intuición, símbolo, sin limitarse al logos occidental. Sin embargo, el lenguaje instiucional favorece el concepto de teología. Poblaciones como la quechua, aymara, mestiza, tienen sus propias categorías teológicas y las aportan a otros pueblos, pues la teología no se rcduce a un pensar ilusurado y de especialistas.

Veamos, primero, lo que llamamos manantiales de esta reflexión y luego los avances metodológicos con las implicaciones que son relevantes para teologías hermanas (de la mujer, del negro, del mestizo, de la teología sistemática de la 
liberación) y, en general, para otras teologias (la teología especulativa y positiva, las tendencias contemporáneas). Me concentro, pues, en fuentes y en procedimientos. No abarco ahora los grandes temas de la teología aymara-cristiana: el conocimiento humano de la divinidad, la mística, la Pachamama, la sacramentalidad, la ética, la eclesiología, la teología del reino y del Espíritu, María, la misionología.

\section{Manantiales de analogía}

Las corrientes de buena agua teologica brotan en todo el acontecer andino, compuesto por elementos quechuas, aymaras, mestizos. Se trata de manantiales de una sabiduría que relaciona entidades distintas, que evoca matrices, que dice más de lo que dice... porque está atenta a la revelación de Dios. ¿Cómo? En nombres y conceptos que de modo analógico se refieren a lo transcendente. Los manantiales andinos muestran cualidades de comparación y relación mulua, de semejanza y diferencia, entre el creador y las criaturas. Teológicamente son conceptos del ámbito e identidad andina aplicados a la realidad sagrada. Es un hablar y pensar posibilitado por la participación de la humanidad en el ser divi$\mathrm{no}^{2}$.

Voy a repasar los siguientes manantiales: visión de conjunto, arte, lucha por la vida, lógica ritual, tradición oral. Estas corrientes de agua fresca evidencian la vocación teológica del pueblo de Dios, su percepción y comunicación analógica de la fe, que enriquece otros modos de pensar.

\subsection{Visión de conjunto}

La realidad es entendida como interacción entre seres vivientes, interacción complementaria entre la divinidad, astros, agua, tierra, plantas, animales, humanos, difuntos, y todo lo demás ${ }^{3}$. En 1613, Pachacuti Yamqui, cronista aymara del Collasuyo, transcribe el diagrama cosmológico del templo del sol en Cuzco. De la divinidad Wiracocha (que es cari, esposo y varmi esposa) provienen el sol (masculino) y la luna (femenina), estrellas, pachamama (madre tierra) y camac pacha (seflor de la tierra) por un lado, y mama cocha (madre mar) por otro lado, hombre y mujer. Es, pues, un paradigma con jerarquía y reciprocidad.

Quechuas de Pinchimuro, entrevistados en 1974, testimonian el intercambio entre la comunidad y sus seres sagrados, en especial la Pachamama, un intercambio que incluye la oración a Dios y a la Madre Marfa:

Pachamama sabe parir ... pidiendo a Dios le entregamos la semilla... Eso que entregamos ella pare... Adoraban mucho a nuestra Madre. Por eso los productos de Pinchimuro eran buenos.

La vida es trabajo (del campesino) y don (de la divinidad). La cosmovisión andina conjuga esfuerzo humano y donación transcendental en una eficaz mu- 
tualidad.

En relerencia a eso hay una comprensión del conflicto. Por ejemplo, Gregorio Condori tiene su versión de la conquista del Perí y del mito del retorno de Inkarti:

Se enviaban nolicias no en papeles, sino en hilos de vicunta; para malas noticias eran hilos negros; para buenas noticias eran hilos blancos. Estos hilos eran como libros pero los espanoles no querían que existiesen y le habían dado al Inka un papel: este papel habla diciendo ¿dónde está que habla? Sonseras, quieren engafiame. $Y$ habia botado el papel al suelo. El Inka no cntendía de papeles. ¿Y cómo el papel iba a hablar si no sabía leer? Así se hizo matar nuestro Inka. Desde esa vez ha desaparecido Inkarey. A todos ellos habían matado los espafias. Pero ahora yo digo: ¿Qué dirian los cspañas cuando vuelva nuestro Inka?

Es ésta una visión basada en una reciprocidad sagrada desde la cual se comprende la ruptura de la conquista y colonización. En la actualidad predomina la aspiración del progreso, el subjetivismo, el conocimiento con esquemas de sujeto-objcto y causa-efecto. Esto ya forma parte de la cosmovisión andina, combinada y en tensión con las herencias propias, y comúnmente supeditada al paradigma del intercambio recíproco. La clave, pues, es conocer la participación entre los scres y no la mutu exclusión, aunque esto ocurre cuando dicha particinación es violada.

\subsection{Arte autóctono}

En la elaboración artística hay señales del alma y de la teología de este pueblo. El arte dinamiza los ejes de la existencia: ciclo ritual y festivo, orden espacial familiar y comunal, amor, ceremonias, juegos, lenguaje, trato socialt. Más a fondo, el arte consolida visiones espirituales del mundo. En la codificación arústica encontramos vestigios de la presencia del Espíritu; unos vestigios que el mismo pueblo captu y reproduce.

En contraste con el intercambio social utilitarista modemo, el comportamiento autóctono viene mayor sensibilidad hacia el otro y hacia el misterio de la existencia. El gesto corporal, la cuidadosa secuencia en cada clase de conversación, la estructura de dar y recibir, el sentido cualitativo del tiempo, en fin, un sinnúmero de detalles manifiestan el arte de convivir. Un ejemplo de trato amoroso es la canción de Zacarias Puntaca:

¿Para qué te habré conocido?

Convirtiendo la noche en día solamente a ti te busco, caminando sin rumbo... 


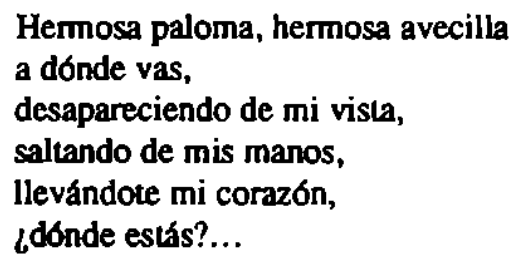

Este hondo y delicado trato hacia el projimo apunta también hacia el Otro. Con respecto a la producción musical, ésta trasluce espiritualidad e, implícitamente, teología El sikuri y la zampoña están en las manos y pulmones de gran cantidad de campesinos aymaras. Como explica T. Turino, cada par (guía y contraguia) y el conjunto tienen que "sonar como un instrumento", tocar contrastes en pequefia escala y continuamente repetir melodías. Así hay un sentido duradero del universo, una fuerza unificada entre seres humanos y una comunión musical con la divinidad, ya que está ubicada cultualmente.

En general, la estética aymara es mediadora. Así ocurre en el mito, los coloridos del tejido, el juego, el dibujo, la selección de semilla (según el fino análisis de Verónica Cereceda). La belleza produce "un enlace o paso entre dos términos contrarios (enfermedad-salud, vida-muerte, natural-sobrenatural, opaco-brillante)". Cereceda muestra cómo el aymara expresa conjunción en los terrenos de la belleza, el amor y el placer, y muestra disyunción en los campos de la mente, el dolor, la agresión.

Mediante sus contenidos simbólicos el arte ingresa en la comprensión teologica. La población aymara dice poco con argumentos y dice muchísimo con la coreografía de una danza religiosa, el modo de construir la vivienda, los tonos y contrastes de colores rituales, el silencio que permite un compartir profundo. De esta forma afirma su espiritualidad, la presencia transformadora del Espíritu de Dios.

\section{Lucha por la vida}

Junto con la inmersión en la nauraleza y sus ciclos, y la milenaria paciencia ante reiteradas adversidades, la población andina también impugna, se organiza, percibe nuevos horizontes. Esta movilización por la vida se da sobre todo en pequethas dosis: en la tradición comunal en el campo y la ciudad, en el esfuerzo diario por conseguir alimento y jornal de trabajo, en la reivindicación ante el municipio y el Estado, y en una gama de agrupaciones (artesanfa, deporte, sindicato, música, grupos de mujeres, de jóvenes, proyectos comunitarios). Resalta el cálculo de logros escalonados y posibles, y no la fantasía de una mutación total. También hay un sentido de rotación y democratización de responsabilidades. Por otro lado, campea la desconfianza mutua y el control sobre la autoridad mediante la crítica oral. 
La transcendencia de la lucha suele ser expresada por las personas-líderes. Estos son dos rasgos comunes: gente desvalida visualiza una gran fuerza colectiva y redescubre una religión consoladora y prácticas. Por ejemplo, una niña de Chunchuquru manifiesta, así, la nueva identidad andina:

En mi pueblo de Collasuyo

ayer como anteayer

engañados nos encontramos

los Aymaras.

Mañana, pasado mafiana, me encontraré alegre entre wodos los aymaras en el pueblo de Collasuyo.

Una trabajadora de Bolivia, Ana María Condori, da este testimonio:

Sería mucho mejor para las jóvenes del campo saber cómo es trabajar en la ciudad y no ilusionarse en vano... y no sean como yo, que me sentra casi nada cuando fui a la ciudad...

Preferimos estar afuera donde hay que pelear, a estar en la casa aislada. Yo me sentía muy feliz de estar en un bloqueo que ya es nacional; sentía que estaba aportando y eso da mucha fuerza...

Me di cuenta que en la lglesia se habla de los pobres, de los enfermos pero solamente orando, hablando y ıqué? La religión en sí me gusta, no es mala, muchas veces me ha reconfortado, pero no aguanto la resignación y el encerramiento.

Estos rasgos de fortalecimiento mutwo y fe luchadora incluyen una comprensión de la salvación cristiana.

Aún más, los testimonios de líderes, y prácticas mancomunadas, esbozan analogías cristológicas. Por lo común, la figura y el mensaje de Jesús no están en primer plano, debido a largas carencias en la evangelización. Pero la fuerza liberadora, solidaria, palpita con una perspectiva pascual de pasar por la resignación y muerte hacia la vida.

\subsection{Lógica ritual}

Cada secuencia de comportamiento sagrado, referido a necesidades básicas, y el universo rilual aymara tienen su racionalidad creyente. No voy a detenerme en el análisis de estos hechos ${ }^{6}$, sino más bien en sus ingredientes teológicos.

El corazón del rito es renovar una tradición comunal y espiritual, mediante símbolos enraizados en la cotidianeidad que oscila entre lo benéfico y lo maléfico. Lo simbólico, estructuralmente polivalente, puede ser percibido de varias 
maneras. Caben además unas interpretaciones científicas. Por ejemplo, en una lectura inspirada en C. Levi Strauss se detectan oposiciones binarias: arribaabajo, varón-mujer, luz-oscuridad, crudo-cocido, frio-caliente, bondad-maldad, derecha-izquierda. Estos binomios complementarios muestran la estructura mental en su versión aymara. Pasando a una lectura teológica, uno constata la lógica ritual de sacrificios-ofrendas-recepción del don divino. Así la población aymara explicita la reciprocidad mutua y con un Dios sustentador absoluto de la existencia.

Detengámonos en la ch'alla que, a mi entender, sintetiza la simbología quechua-aymara. Como todos saben, esta libación de licor dirigida a una entidad transcendente es hecha por un varón y una mujer en momentos claves: trabajo, ciclo vital, fiestas cristianas, transacciones económicas, encuentros humanos, eventos políticos. Con ella se propicia el bienestar y se rechaza o se exorciza la maldad. Generalmente la libación es hecha a favor de Pachamama y en dirección al oriente donde nace el sol. También se invocan figuras cristianas y se hace la señal de la cruz. Así, una lógica indígena pasa a formar parte del crislianismo-andino. Conlleva una ética autóctona: brindis de comunión y abrazo de paz al recibir la bendición divina. Tenemos pues símbolos de fe, rito, ética, comunidad, que señalan una teología integral.

También podemos recorrer, como hace Xavier Albó, la hisloria personalcomunal y sus rituales, descubriendo la búsqueda de "equilibrio entre el mundo de arriba, más ordenado y distance, y el de abajo-adentro, a la vez más peligroso, más cercano, y más creativo"', y, por otra parte, detectar ceremonias urbanas dirigidas a dioses del dinero y prestigio. A fin de cuentas, el universo ritual nos hace pensar en la densidad de cada momento y espacio, en la via sacramental para acercamos y ser locados por el misterio, y también en la conflictividad humana donde hay elementos buenos y malos atribuidos a Dios.

\subsection{Tradición oral}

La teologia católica comprende la revelación como recibida por la Iglesia universal e inculturadamente. Esta comprensión se lleva a cabo con las herramientas propias de cada pueblo. En el contexto aymara - como en otros sectores indigenas -, los instrumentos conceptuales ordinarios son de carácter oral: suenos socializados, que en muchas ocasiones indican qué hacer 0 no hacer; mensajes de los difuntos y de otros seres sagrados; cuentos que parecen intranscendentes, pero son monumentos de sabiduria; relatos con la etiología del lugar, como un mini-génesis; los mitos andinos fundantes, que explican cosas, personas y demás seres (en especial, mitos de los Wiracochas, dioses y héroes de la civilización andina). Existen también sociogonías, como las leyendas de los hermanos y hermanas Ayar que sostenian el poder cusquento. Por otra parte, existen relatos sobre Inkarri (como el ya citado de G. Condori) y sobre Kollarri. Se da también el mito modemo, afianzado en estas últimas décadas en torno a la 
escuela, la máquina, el dinero, el progreso. Toda esta cambiante tradición oral tiene distintos ángulos, que pueden ser estudiados por la antropología, la semiología y la historia. La óptica teológica descubre en dichas formas de conocimiento popular una comunicación transcendente: las huellas de cómo el Dios cristiano se revela al pueblo pobre. Consideremos dos casos.

A orillas del Lago del Altiplano, Ricardo Laura' ha recogido una enseñanza sobre lo principal del mundo andino: la reciprocidad y, si no se da tal comportamiento, la desgracia.

Un día a Quri-Marka (pueblo de oro) llegó una mujer pobre, cargada de un bulto grande, y cansada buscando donde alojarse y luego nadie quería darle alojamiento. La mujer pobre visiló a una familia muy adinerada y tacaña. El había dicho que duerma en su patio nomśs, sin prestar frazada ni dando comida, y cansada se quitó su bulto: "voy a ir por el pueblo para dar una vuelta", diciendo habla dejado su bulto.

Viendo el bulto, esta familia se interesó en desatarlo, diciendo: "habrá oro o plata". Al desatar el bulı sólo encontraron un cántaro grande y al destaparlo sólo vieron agua que comenzó a correr y por gusto intentaron taparlo. Luego de dos días el agua inundó las chacras, murieron los animales, quizás se salvaron unos cuantos.

Todo esto hahía pasado porque no dieron alojamiento a esa mujer pobre. Por eso hoy en día se dice: "donde están los pobres allí está Tatitu Dios".

Ouro ejemplo. Cada año, de Paucarcolla, altiplano quechua, va un grupo de danza a la fiesla mariana de Paucarbambo, cerca de Cusco. Una de sus canciones dice (en parte) $y^{\prime}$ :

Traemos nuesiras almas/amarradas de pecado.

Dicen que tú, Madre/las desatarás/con tus cinco dedos de rosas.

Dicen que ú eres/la que nos quiere, dulce María.

Tú pues, Madre, nos llevarás/hasta el centro donde está tu Hijo...

Con tu aprecio nos fortaleceremos/para vivir alegres...

Danos tu bendición Mama/con tus manos de cinco rosas.

Fortalecidos con tu bendición/regresaremos a nuestros hatos.

En este canto, como en otros elementos de santuarios marianos, aparece la dialéctica entre pecado y redención (bendición), cuya mediación es una representación femenina de lo sagrado. En efecto, María, la madre de Cristo, es quien interviene, con su inconmensurable amor, fortaleciendo y llenando de gozo al pueblo humilde que la festeja. La mariología abunda en la tradición oral que es como la Biblia de la multitud.

Por otra parte, algunas comunidades cuentan con instrumentos conceptuales 
extraordinarios: lectura comunal-práxica de la Palabra, ensertanza de la Iglesia sobre el Dios de la historia, reflexión sacramental y ética. Llama la atención la calidad con la cual la población indígena y mestiza interpreta los datos de la revelación. Por ejemplo, en Semana Santa entienden que Cristo nos salva del pecado, con repercusiones para las mayorias que sufren enfermedades, y el Vicrnes Santo se recogen las hierbas medicinales. En los programas de catequesis y otras instancias hay una genial relectura del mensaje de salvación.

\subsection{Sabiduria aymara y teología cristiana}

Como hemos anotado, hay manantiales de sabiduría aymara y quechua en la cosmovisión de una reciprocidad sagrada, en el arte y en su espiritualidad, en el esfuerzo por vivir y ser liberados de todo mal, en los ritos con su racionalidad simbólica y cn la tradición oral que, directa o indirectamente, trasluce la revclación. Estos elementos captan analógicannente la relación Dios-seres humanosmundo, dada la correspondencia y diferencia entre la experiencia humana y la manifestación de Dios.

Esla captación a veces es resumida en una "confesión de fe". Un credo de personas aymaras dice así:

Creo que Dios ha creado la tierra, los cerros, el lago,

y por eso producen nuestros sembradíos

...en la unidad de nuestras comunidades

y en la sabidurfa de ancianos y ancianas,

...en la lucha contra el hambre,

en la resurrección de los pueblos,

en la justicia para los encarcelados,

...en la sanidad de los enfermos

con las yerbas que crecen en las pampas,

...en el ofrecimiento de Jesucristo, por todos,

y en la misa para los productos (ch' uxĩa misa)

...en la manifestación de Dios,

mediante los protectores y los Achachilas,

...en que toda oración es escuchada por Dios,

porque en El viene la vida eterna,

para todos los pueblos

...y que el Espiritu Santo ha venido

para liberar al ser humano de la mano del demonion'10.

Así se entretejen las principales realidades andinas: tierra, comunidad, esfuerzo social, Dios, seres sagrados, hambre, oración, elc. Están entretejidas por 
un pueblo creyente y pensante. Ahora bien, este tejido autóctono, ¿qué dice a la teología cristiana?

Dice que ella, como cualquier teología, está involucrada en las realidades básicas de la comunidad creyente. Entonces, toda fe y su reflexión habla a y sobre Dios con una imaginación analógica. Por lo tanto, no afirma un mundo espiritual segregado de nuestras realidades básicas.

La población andina tiene su sabiduria (aunque a menudo sea juzgada como semi-ignorante). Ella capta las honduras de la revelación gracias a la acción del Espíritu. Es bien obvio que el Espíritu, y no la habilidad humana, hace conocer la gracia y hasta permite tener la mente de Cristo (1Cor 2, 10-16). Este modo paulino de conocer es verificado por los "ignorantes" y "pequeños" de hoy. Cuando uno camina junto con esta multitud pequeña-sabia, se entiende que lo que puede guiamos para llegar a la verdad (Jn 14, 26) no es una argucia profesional, sino sólo el Espíritu.

Por otra pare, la sabidurfa andina tiene limitaciones y necesita dejarse guiar por pautas veraces. Ella no proviene directamente del Espíritu. Es un pensar humano con ambigüedades y con dificultosa adecuación a los crilerios de la revelación. En este sentido, la Iglesia con su magisterio tiene maneras de sopesar esta y las dernás teologías, de ver en qué medida una teología inculturadamente andina es fiel a las fuentes de la revelación.

¿Cómo se lleva a cabo este discernimiento? Si el instrumental doctrinal estó ofuscado por el peso de otra cultura, entonces hay cortocircuilos. Por ejemplo, teologías de "la palabra" y de "la historia de salvación" suelen descalificar lo cósmico-animista. Pero un buen discemimiento debe ser teocéntrico y pneumálico, y debe examinar cómo los conceptos andinos, en nuestro caso, dan cuenta de la automanifestación de Dios, la encamación, la obra del Espíritu, la Trinidad que redime la condición humana.

\subsection{Implicaciones para otros cauces}

La sabiduria creyente de pueblos indígenas-andinos, ıqué implicaciones tiene para los puntos de partida de otros modos de pensar telógicos?

Teologla mestiza". Piensa la fe desde la matriz consuituyente de América Latina, desde un ethos cultural y político mestizo, sellado por la evangelización. Hay una concatenación entre religiones del pueblo, sabiduria, teología inculturada. El mestizaje es enunciado como un hecho, pero no como portador de teología. Si estuviera atenta a los manantiales indígenas, y si revisara la tradición cristiana a partir de categorlas mestizas, entonces descubrirfamos muchos rostros de Dios en las mayorias mestizas del continente.

Teología negra ${ }^{12}$. Su punto de partida es la herencia y experiencia históricocultural afro-americana (W. Amado); el sujeto de la teología es negro, comuni- 
Lario, cotidiano, pero inserto en un proceso mayor de liberación de la mujer, del indígena, del niño (Marilla Shuller), y plantea que Jesucrisı es negro porque "en su proyecto salvífico él asumió la causa de la víccima" (Antonio da Silva). Sus mananuales, así como los indigenas, son la identidad y la labor liberadora. Pueden, pues, juntas confrontar los ídolos anti-indio y anti-negro que se infiltran en el crisuanismo latinoamericano. Al dialogar con el pensamiento indio fiel a la Pachamama, la teología negra aporta la visión de una tierra nueva, escatológica.

Teologla de la mujer ${ }^{13}$. Esta reflexión brota de una convivencia primordial, liderazgo de mujeres, inserción en medios populares, teólogas mujeres, que, según Ivone Gebara, elaboran teología con arte y simbología, y no sólo con la razón. Maria C. Bingemer descubre los dualismos de cuerpo-alma, cielo-tierra, eficiencia-gratuidad, que conllevan un Dios masculinizado, mientras que la Trinidad no es patriarcal, ya que es comunidad de amor e integradora de lo masculino-femenino. Toda esta teología comparte con su "hermana india" las buenas aguas del símbolo y de la analogía. Si se suman la cosmovisión autóctona con la causa de la mujer-varón, tendremos una perspectiva de reciprocidad radical.

Teología sistemática de literación ${ }^{14}$. Es producida por el conjunto del pueblo de Dios (comunidades de base, agentes pastorales, magisterio jerárquico, teólogos profesionales) y por sujetos concretos: mestizos, negros, mujeres, indígenas, clases medias, etc. Clodovis Boff ha desentraffado las mediaciones socio-analíticas y la sabiduría popular, las mediaciones hermenéulicas a partir de la Biblia y de toda la tradición cristiana, y las mediaciones prácticas, en interacción con las otras dos. Esta reflexión sistemática provee a la teología andina de un hilo conductor (la relación pobre-Dios) y una metodología (como la explicada por C. Bolf). Y, a su vez, la perspectiva de liberación cuenta con aportes indígenas sobre la divinidad, las estructuras sacramentales, la ecología, la eclesiología comunitaria-festiva, y no sólo un aporte cultural-étnico.

Teologías contemporáneas del primer mundo ${ }^{15}$. Las teologías autóctonas invilan a la corriente especulativa a dialogar con racionalidades distintas a las griegas-occidentales. A la corriente positiva (en especial, a las teologías de "la palabra" y de "la historia de la salvación") le abre ricos manantiales -como los ya descritos- y el horizonte de un saber ecuménico. A las teologías sistemáticas (ya sea de la tendencia liberal, que reconcilia al cristianismo con la modemidad, ya sea de la tendencia neo-ortodoxa, cuyo cristo-centrismo excluye sabidurías marginales), les ofrece, como plataforma, la paradójica alianza entre Dios y los últimos de la tierra.

En conclusión, los puntos de partida, los manantiales de la teología forjada por comunidades creyentes indígenas, analógicamente correlacionan y diferencian este mundo, la humanidad, los seres sagrados, Dios. Esto vale para ellas, y vale también para ouros tipos de reflexión de fe. Quiero presentar, a continuación, unos elementos metodológicos que también interpelan a otros modos de pensar.

Digitalizado por Biblioteca "P. Florentino Idoate, S.J."

Universidad Centroamericana José Simeón Cañas 


\section{Avances metodológicos}

En términos prácticos, un método orienta la elaboración colectiva. Como dice B. Lonergan, es "un marco de creatividad en forma colaborativa"16. Es decir, una buena metodología no constriñe; por el contrario, encauza esfuerzos creadores.

La teología autóctona est́ avanzando por los procedimientos delineados por comunidades y agentes pastorales, por una sistematización en eventos ecuménicos y por una labor profesional. Todos ellos son marcos de creatividad, a partir de los manantiales ya explicitados. Son pautas de colaboración que, pluralista y analógicamente, hablan de Dios.

\subsection{Instancias en la reflexión}

Comunidades con identidad quechua, aymara, mestiza, reflcxionan autónoma y periódicamente. Se trala de una producción informal de imágenes y conceptos referidos al trabajo, la familia, la comunidad, la historia local, los ejes rituales. Emplean una metodología narrativa, cordial, sincrética. Narran contactos entre seres humanos, cosas, espíritus, manifestaciones sagradas. En la conversación corriente y en relatos estructurados la población andina piensa a Dios con las analogías de su medio ambiente y su ser comunal. En lugar de fórmulas mentales tienen categorías cordiales y lundantes: protección de Dios, castigo divino, ofrenda y sacrificio, adoración, fícsta, perdón, comunión. Es un métode sincrético que entrecruza conocimientos autóctonos, reinterpretación del cristianismo, asimilación de la modemidad y cultura popular emergente.

Esta elaboración informal es ahondada en reuniones y ceremonias. Yatiris y otros líderes aymaras, altomisayoq, paqo y demás sacerdotes-pensadores-médicos quechuas, mujeres convocadoras de lo religioso, cada uno o una, a su manera, tiene un rol teológico. En las asambleas comunales los portavoces de la tradición logran poner en contacto asuntos de intcrés común con la espiritualidad y ćtica andina. Por otra parte, las ceremonias suscitan un pensar simbólico y ritual. Signos de la naturaleza (coca, dulces, alcohol, animales, tierra, roca) y signos de la comunidad (danza y música, gestos de ofrenda y otros más) scñalan modos de entender la divinidad. En esta metodología, la oración es, no un paréntesis ni un apéndice, sino uл componente en la maduración del pensamiento.

Los eventos cuyo objetivo es reflexionar la le tienen otro orden metodologico $^{17}$. Lo anterior es retomado, pero ahora hay una sistematización teológica indígena. En 1986, la Consulta de Quito reflexiona en torno a "líneas básicas" en la humanidad: tierra, organización, creencia, proyecto de liberación. Estos son, a mi parecer, ejes permanentes en la teología llamada "india" y en cualquier reflexión fundante. En cada eje se indaga la respuesta de la Iglesia, y la religión indigena se convierte no ya en un objeto a redimir, sino en sujeto de diálogo. Dicha Consulta opta por la analogía: "que la teología verse sobre la 
tierra, la comunidad, la misión, el trabajo, la política, la transcendencia, la ética, el rito" -decía un participante. No pensamos a Dios a secas, sino con metáforas de la tierra y demás ejes de la existencia.

Otro gran avance es tomar en serio el universo religioso aymara, ya que éste tiene consistencia teológica. El taller del CTP en 1987 aquilata la opresión sufrida por este pueblo (que incluye elementos religiosos) y los caminos de liberación (que incluyen religión aymara y fe cristiana). Aún más, a la luz de la fe aymara se elabora un conocimiento del misterio de Dios. Así lo plantea el taller teológico en Chucuito, en 1990. Luego de celebrar una "dulce misa" se dialoga sobre qué pensamos de Dios: "Dios amanece, anochece, junto con nosotros... Nos ve, nos escucha, nos pastea... Ya sea entristecimientos, alegria, siempre nos acercamos y pedimos a Dios con toda le y sentimientos, por lo que después ya estamos libres... Siempre recordamos a Pachamama con nuestros ritos". Estas creencias propias, sincréticas, liberadoras, son condición de posibilidad del conocimiento de Dios.

También se está gestando una síntesis. Me parece que esto es lo que caracteriza el encuentro pan-andino en Chucuito y el latinoamericano en México, ambos en 1990. El primero conjuga conceptos cosmológicos e históricos de lo sagrado, la teología tiene al pobre y sus culturas como protagonista, la rellexión brblica dialoga con mundos indígenas -aporte dado por G. Gutiérrez-, apreciación cristiana de creencias y ritos - ponencia de Domingo Llanque. En México se asienta una "melodología india". Esta reunión teológica tiene como ingredientes la celebración, el diálogo, la rellexión, los acuerdos de consenso. El método es delineado por culturas, pero no sólo por ellas, sino también por los procesos sociales y las tareas evangelizadoras.

El evento de México precisa unas pistas. Sujeto teológico es la comunidad con sus sabios y sabias, comunidad enraizada en la tierra y que vivencia y celebra a Dios padre y madre. Las culturas autóctonas, con su pasado y porvenir, ingresan en la agenda teológica, y son leídas críticamente con la ayuda de las ciencias sociales. También el pensar creyente considera los procesos sociales, en los que la vocación indigena se aúna a otras energias que apuntan conjuntamente hacia mulaciones globales. En fin, no cabe duda que la teología india ya tiene su metodología, y dialoga con otros para, todos juntos, aportar a la liberación sin límites.

Me parece que estos avances muestran una calidad teocéntrica cuestionadora del antropocentrismo que campea en ambientes cristianos, un método definido no por el subjetivismo de quien piensa, sino por la recepción humana de la manifestación de Dios. Contiene analogías cristológicas, dada la comprensión indígena de las mediaciones encarnadas de la revelación. Además, el método es definido no por élites logocéntricas, sino por el amplio conocimiento simbólico del pueblo de Dios. 


\subsection{Animación profesional}

En la concatenación entre la producción de base y el aporte especializado, este último - como advierte X. Albo- escucha, aprende $\mathrm{y}$, desde su propio ángulo, ofrece unos elementos ${ }^{10}$. Es un proceso que subvierte edificios mentales y que reconstruye moradas. En un ensayo anterior, esboce los retos al interior de la teología aymara: paso de la elaboración oral a la escrita, sincretismo aymaracristiano que confronta, entre otras cosas, la actual idolatría econónica, eclesiología ecuménica que desafía programas eclesiales y una visión liberadora con particularidades aymaras que -como explicaba Encarna Huanca- es "una rafz que nadie puede matar... y que ofrece esperanza". A continuación deseo resumir algunas direcciones metodológicas.

La teología aymara tiene, en primer lugar, un rumbo cotidiano. No lo prosaico ni lo pasajero. Sí lo profundo de cada día y de cada ser humano. Los "cimientos" de la teología, según X. Albo, son las perspectivas acerca de la tierra, de la comunidad, del cosmos. Albó también descubre el rostro aymara del Dios liberador por analogía con actitudes humanas centrales: reciprocidad y don mayor que lo recibido, reconciliación, comunión con el universo, respeto y confianza en Dios y en seres sobrenaturales, esfuezzo humano y apoyo de Dios, tarea de unir a codos los sectores aymaras.

En segundo lugar, es una reflexión orientada por una síntesis. Dorningo Llanque define la teología así. "El aymara piensa y se relaciona con Dios y con el mundo sobrenatural". Es un pensamiento relacional que ve a la divinidad más allá de un sistema cultural, ya sea el hegemónico occidental o el indígena-en-sí. Es un pensar alento a la dinárnica de síntesis: "no hay contradicción en el uso de elementos de origen católico y de origen autóctono". Es una síntesis creativa, ya que la teología "abre las puertas de la catolicidad de la Iglesia en la cual caben otras nuevas maneras de ser cristiano". Entonces, el aymara, junto con la reivindicación del pensar propio, exige una real universalidad abierta a aportes de iglesias particulares y sus teologias.

Otra dirección metodológica se refiere a la verdad-práctica. La monumental obra de Enrique Jordá pone en diálogo el mundo aymara con la tradición cristiana-bíblica desde criterios de ortodoxia y ortopraxis. Interesa, pues, una teología con rectitud en el pensar y en el actuar. Jordá aprecia cómo la fe en Dios y en "servidores" (seres sagrados andinos) es expresada "con categorías andinas", valora la cristología, señala carencias en ésta y plantea la pneumatologia como campo de trabajo teológico.

Una última orientación -en continuidad con la de D. Llanque- puede resumirse con los términos de "aymarización del cristianismo". Esto ocurre, según los macizos aportes de Hans van den Berg, en las concepciones del tiempo y del espacio, de la fiesta, de los seres sobrenaturales cristianos, de la cosmovisión. A fin de cuentas se trata aqui de una "religión aymara-cristiana" 
en que cada têrmino influye en el otro y da como resultado una "totalidad coherente". También se puede decir que se da una aymarización de la teología, ya que este pueblo ha incorporado y recreado la tradición cristiana.

En resumen, los profesionales no aportan elucubraciones enigmáticas, sino respuestas precisas a la pregunta de cómo se hace teología. Hacemos teología en la cotidianeidad, con un sentido de síntesis, con onodoxa-praxis y aymarizando la labor teológica.

Merece la pena afiadir algunas pistas provenientes de otras latitudes y que son relevantes también para regiones andinas ${ }^{19}$. El modo como Clodomiro Siller analiza el relato nahuatl sobre Guadalupe invita a una mayor sintonía con lenguajes indígenas (flor como sabiduria, espiritualidad, música de la le). Aiban Wagua plantea el hacerse discípulo-teólogo (como el ha aprendido del "saila" Iguanabiginia) y la fidelidad a la visión de cada pueblo (por ejemplo, la divinidad kuna masculina y fernenina, Paba y Nana, que no son sinónimos de Dios). Pablo Suess muestra que lo indigena no es un tema de la teología, sino que la reorienta. Esta ya no es mediadora entre dos mundos, sino que opta por cl indígena. Por eso, pasa de la monocultura autoritaria a una pluricultura marcada por pentecostés, de la desirucción de la alteridad a un reconocer la alteridad, de un eclesiocentrismo a una teología del reino. Bartoloméu Melia, inmerso en los guaranfes, recomienda al teólogo proceder como el etnólogo, dejándose "interpelar por esa palabra del 'otro' en cuanto experiencia religiosa válida universalmente". De nuevo, es claro que metodológicamente una teología autóctona ofrece, además de sus propias condiciones de posibilidad, las de ouros modos de reflexión dispuestos a captar la universalidad en algo particular. Ahondemos en este punto.

\subsection{Implicaciones para otras teologías}

Los recursos metodológicos que valen en estas comunidades andinas e indoamericanas, es decir, sus "marcos de creatividad" (B. Lonergan), incentivan otros modos de conocer a Dios, a sí mismo y al acontecer humano.

¿Qué implica esto para las teologías hermanas? La metodología que hace un socio-análisis de la esclavitud y demás maldades, y que avanza con la tradición afro-americana y la lectura de la Palabra, queda beneficiada por el pensar indigena. Puede afianzar, por ejemplo, su articulación con hechos cotidianos, haccrse discípulo de sabios o sabias negras y desarrollar un ecumenismo que libera del sectarismo. A su vez, el pensar desde la negritud facilita a la teología india una visión bíblica no racisla y la captación de un Cristo en la causa de todos los marginados.

Con la teología de la mujer comparte cualidades metodológicas: es una teologia concrela, comunal, relacional, celebrativa. También le ofrece la dialecticidad indígena de vida-muerte y las analogías sobre Dios que brotan de univer-

Digitalizado por Biblioteca "P. Florentino Idoate, S.J."

Universidad Centroamericana José Simeón Cañas 
sos autóctonos. Por su parte, la mujer piensa la revelación con categorias conjuntivas. Resalta, por ejemplo, el Espíritu de verdad que reside en la comunidad creyente (Jn 14, 17), y la tierra futura, la "Jenusalén de arriba" como "nuesura madre" (Gal 4, 26).

En la medida que la teología india establece relaciones mutuas con la teología mestiza, la primera da a la segunda algunos fundamentos imprescindibles, como el método de reciprocidad y no de subordinación; y la segunda aporta a la primera una lógica sincrética y moderna. Por un lado, se dan procedimientos relativamente autónomos - los indígenas- y, por otro, un método de comunicación y simbiosis - lo mestizo-. Esto último le permite canalizar conexiones de lo indigena con el espectro de racionalidades contemporáneas.

En cuanto a la teología sistemática de la liberación, recibe de parte de la reflexión autóctona unos matices de espiritualidad y líneas articuladoras de un pensar simbólico y un pensar teológico. A su vez, la sistemática formula una exigencia: no limitarse a una etno-teología, sino desarrollar todo el cwriculum. También le recuerda la supeditación a la tradición cristiana, ya que pensamos la fe no de acuerdo a caprichos intelectuales, sino según la norma de la revelación.

Con respecto a las grandes corrientes teológicas contemporáneas, la renexión especulativa es invitada a considerar la riquísima mítica indígena. A la corriente positiva le aporta la lectura inculturada y militante de la Palabra que realizan las comunidades marginadas. A las perspectivas liberales, por un lado, y neo-ortodoxas, por otro, les ofrece la inquieud fundamental: cómo dialogar con las "teologías del pobre" y traducir la racionalidad a categorías contemporaneas.

Ahora bien, en lodo esto no se trata de un mero sistema de prestamos de ideas y comparaciones entre modos de pensar. Las correlaciones tienen, más bien, una meta de fondo. Se trata de que cada teología sea fiel a los datos de la revelación-salvacion. Intentamos conocer mejor la fe que está en correspondencia con la Palabra y con la pascua. En este sentido, la teología mexicana ha dado un salto cualitativo al considerar que la metodología de los pueblos indígenas tiene como cimientos tanto la revelación como la salvación. Se ha tomado en cuenta la voluntad salvífica de Dios para todos, pero hace falta profundizar la revelación ofertada a todos ${ }^{20}$. El Dios cristiano se revela a toda la humanidad, incluyendo a quienes tienen religiones sincréticas y no-cristianas. Siguiendo esta pista, la teología asimila las sabidurias indigenas y mestizas.

Adcmás, para quienes somos católicos, hay aún mayores exigencias metodológicas. Es necesario aproximarse a la verdad integral: como indica el Vaticano II, "investigar a la luz de la fe toda la verdad contenida en el misterio de Cristo" (Dei Verbum, 24). Comenzamos con la palabra escrita que es como "cimiento" y "alma" de la teologia, y sopesamos los "signos de los tiempos" (Gaudium et Spes, 44 y 62). Indagamos la verdad, no en un vaclo, sino con analogías y 
métodos desarrollados por la comunidad creyente. Más en concreto, la comunidad aymara ¿qué dice de Dios? ¿Cómo es su pacha-sophia?

\subsection{Comprensión aymara de Dios}

Un método teológico vale en cuanto es capaz de hablar del misterio. Ya sabemos que esto ocurre en los mundos indígenas del continente con variados lenguajes: gesto ritual, calor humano, relato de un milagro, y tantos más. Son lenguajes que no disocian materialidad y espiritualidad. $O$, mejor dicho, "sentimos la presencia de Dios, a partir de la tierra, porque ella es la médula de la teología"21. La teología aymara se inicia al pensar a Dios-tierra (y otros símbolos), porque el misterio se revela a la humanidad concreta y transcendentalmente.

Como en muchas otras culturas, lo sagrado es atrayente y también es amenazante y peligroso. Lo bueno, por un lado, y lo malo, por otro lado, provienen de seres sagrados. Por eso hoy se entiende al Dios cristiano con facelas benéficas y maléficas. $\mathrm{O}$, como dice la gente, Dios nos bendice, Dios nos castiga. Así, la realidad contradictoria es inseparable de Dios.

Me voy a limitar a aspectos cotidianos y elementos críticos en la comprensión aymara (y andina) de Dios, y luego voy a delinear un discernimiento que incluye pautas biblicas.

Se trata, en primer lugar, de un conocimiento desde el aquí y ahora, un pensar a Dios desde lo aparentemente "insignificante". La celebración (comer y tomar, música y danza, (raternidad, gozo, oración, rito) conlleva armonía con el cosmos y certeza de que Dios alegra. Los procesos de reproducción, vegetal, animal, humano, manifiestan una tierra-Madre y una vida-Padre. Al trabajar la tierra, y en toda labor económica, se visualiza a Dios como sustentador, creador, seno de lo viviente, principio de acción. La práctica medicinal (empleando hierbas y minerales, terapias integrales, rezos) percibe a un Dios que sana. La familia y la comunidad con sus costumbres tienen un fundamento religioso que apunta al concepto del Dios Amor. El coraje político y la tenaz planificación aymara se correlacionan con una realidad sagrada que convoca y organiza. La sabiduria, transmitida oral y sistemáticamente, tiene un núcleo: Dios nos enseña a vivir bien. Todo esto, puede abreviarse de la siguiente manera:

$\begin{array}{ll}\text { rito y fiesta: } & \text { Dios-alegra } \\ \text { reproducción: } & \text { Madre-tierra y Padre-vida } \\ \text { tierra y trabajo: } & \text { Dios-sustentador } \\ \text { medicina: } & \text { Dios-sana } \\ \text { farnilia y comunidad: } & \text { Dios-ama } \\ \text { política: } & \text { Dios-organiza } \\ \text { sabidurfa: } & \text { Dios-ensefla }\end{array}$

Desde la cotidianeidad (columna de la izquierda), las personas creyentes 
nombran y comprenden a Dios (columna de la derecha). Y, a la vez, estos nombres constituyen, transcendentalmente, el aquí y ahora. Obviamente no hay cabida al agnosticismo, ya que los nombres de Dios hacen comprensible todo lo que existe.

En segundo lugar, es un pensar crítico. Las comunidades andinas interiorizan, a su modo, cuestionamientos modemos. Estos incitan a replantear conocimientos. Al emplear - relativamente- una tecnología modema, la realidad es considerada como objeto de innovación, y Dios es percibido como luente de incesante transformación. La conflictividad, sufrida y reorientada por pueblos marginados permite ver a Dios en la resistencia, en el combate por lo bueno, en la reconciliación que es meta de la pelea. Los sistemas educacional y macroeconómico conducen todo hacia el progreso, pero éste es supeditado a la celebración religiosa. Cada uno trata de progresar, pero lo adquirido por la sabia población andina sirve para hacer más liesta. El juego y el deporte de multitudes, con sus héroes sagrados, ritos seculares, triunfos y derrolas, que son metáforas de vida-muerte de los espectadores, impugnan la imagen del Dios-alegre. La pluralidad de estructuras eclesiales y de religiones también pone en tensión la concepción de Dios que oscila entre un ser parcial y un ser ecuménico. Por lo tanto, tenemos -además de los ya anotados - los siguientes nombres de la divinidad:

$\begin{array}{ll}\text { tecnología modema: } & \text { Dios-humanos-innovadores } \\ \text { conflictividad: } & \text { Dios-resistencia-lucha-reconciliación } \\ \text { educación y economia: } & \text { Dios-progreso-a-fin-de festejar } \\ \text { juego y deporte: } & \text { héroes sacralizados } \\ \text { pluralidad religiosa: } & \text { Dios-parcial-ecuménico }\end{array}$

Estos y otros factores críticos están cambiando la teología de comunidades andinas. Es, pues, necesario un discemimiento ${ }^{2}$, que podemos hacerlo a partir de la racionalidad andina y de pautas biblicas.

Si nuestro punto de parida es el modo de pensar de la población andina, vemos que la divinidad es nombrada en y para la cotidianeidad. Por eso, preguntar si el Dios aymara - y andino- es de la naturaleza o si es de la historia, sería una disyuntiva equivocada, y así sería también erróneo encargarle a la teología reemplazar la cosmología andina por una visión de "revelación en la historia". Venerar a Pachamama no implica encerrar lo sagrado en la "naturaleza". Por otra parte, la "historia" es principalmente el acontecer cotidiano de una población rural y urbano-marginal que está en permanente contacto con Dios. Las experiencias más importantes, trabajo, sexualidad, enfermedad, fiesta, nombran a Dios.

Ahora bien, el rito vincula dichas práclicas con los nombres de la divinidad. En ceremonias familiares y celebraciones públicas hay signos de sacrificio, trabajo, asociación, salud, identidad, signos que conllevan contemplación e identidad creyente. Por eso, el universo ritual y la espiritualidad forman parte del 
pensar leológico, de un pensar que dice cómo es el encuentro-distancia con Dios en el acontecer colidiano.

También es un pensar crítico, al asumir la cosmovisión del progreso y atribuir a Dios el espirilu de la modernidad. Es un complejo proceso social con implicaciones teológicas, que está avanzando en varias direcciones. Sus dos polos son una sacralización de la mercancía y del bienestar, por un lado, y una compaginación del progreso moderno con la trayectoria andina, por otro.

Una controversia adicional es la interpretación teológica de imágenes de fe. Junto con el símbolo principal, la Pachamama, hay muchos seres protectoresliberadores. Me parece que, además de la lógica religiosa aubónoma, tienen una signilicación cristiana; aún más, existe allí una cristología latente. En cuanto a Pachamama, no se diviniza el objeto lierra, más bien expresa reciprocidad con el Dios de la vida partidario del pobre que sobrevive material y espiritualmente en Ella. Es posible decir que, a través de Pachamama, en Dios "vivimos, nos movemos" (Hech 17, 28). Por otra parte, muchos santos y santas, imágenes de Cristo, de María, de la cruz, constituyen una iconografía. Son imágenes protectoras para los pequeños de este mundo, que las festcjan. Son imágenes que conceptualizan de modo indígena y mestizo la presencia encamada del Cristo salvador. Sin embargo, cada una de estas imágenes, según las circunstancias, puede - y a menudo asi ocurte- distorsionar y ocultar a Dios, y pueden ser utilizadas por los pudientes para manipular al prójimo. Son rasgos idolátricos, que deben ser confronlados por un pensar apegado al Dios vivo.

Por último, evaluemos, en base a la temática biblica, la comprensión aymara (y andina) de Dios. No voy a presuponer - como hacen ouros- que el Dios de una historia de salvación estaría contrapuesto a estas creencias étnicas y agrocéntricas. A mi juicio, el desfío mayor es el siguiente: cómo comprende este pueblo a Dios aquí y ahora, y en una tierra nueva - reino, Jerusalén celestial, vida eterna-, que libera a todos los pueblos y personas del pecado. Entonces se capta que realidades humanas, dichas analogicamente de Dios, sf permiten entender cauces hacia el reino de Cristo. ¿Cómo ocurre esto? Sobre todo, comprendiendo el festejo ritual aymara ( $y$ andino) tan enraizados en la condición humana. Se trata de comprender a Dios presente en ritos y celebraciones que apuntan a una vida plena y cualitativamente distinta. Justamente la oración y la fiesta hablan del "más allá" de la salvación, del reino ya bien presente y todavía no.

La revelación biblica muestra a un Dios liberador de los últimos de este mundo, legislador justo, creador, fuente de sabiduria y de alegria, Padre, Hijo, Espíritu, amor, agua, pan, luz, camino, vida. Estos nombres de Dios permiten a la teologla aymara, como a cualquier otra, leer y entender la realidad humana, la naturaleza, la historia.

Cuando dichos nombres son negados, en la experiencia y en el razonar andino, entonces la teologia tiene que hablar de una maldad pecaminosa. En espe- 
cial, cuando hay desunión y abuso entre los aymaras que se niegan y desconocen al Dios amor, o cuando hay egoísmo y maltrato hacia los demás; o cuando uno asimila la propaganda narcisista y la magia del dinero; o cuando la fe se enclaustra y no contribuye a la emancipación. Estas y otras prácticas suelen conllevar la negación teológica. Por olra parte, dichos nombres b́blicos son afimados cuando la comunidad eclesial, presente en la población aymara, comprende su capacidad de amor incondicional; o cuando la labor humana, la fiesta, la medicina - y las demás analogías anotadas- corresponden al modo como Dios se ha revelado.

\section{Conclusión}

Los perfiles de la teologia aymara-cristiana (y otras reflexiones autóctonas en América Latina) tienen la calidad de "altemativa". No es la reiteración del mensaje y la doctrina, utilizando categorias culurales y religiosas indígenas. $\mathrm{Ni}$ es una mera faceta, ya sea en una reflexión cristiana cómodamente insertada en la modemidad, ya sea como "sub-departamento indigena" en la teología de liberación. Su carácter "alternativo" proviene de sus manantiales: cosmovisión de reciprocidad, arte, lucha por la vida, lógica ritual, sabiduría oral. Estos son manantiales de analogía de conceptos adecuados para entender la condición humana y para captar a Dios, semejante y diferente a lo que nosotros somos.

Sus perfiles altemativos provienen también de los recursos metodológicos: teología oral y narrativa, simbolica y espiritual, con una racionalidad indígena de conjunción y síntesis (y demás recursos descritos). He indicado cómo estos manantiales, y también estos métodos, interactúan con sus "hermanas": la teología afromericana, de la mujer, del mestizo, y la sistemática de la liberación, y cómo aportan a grandes corrientes contemporáneas. Pues bien, el conjunto de estos elementos constituye un pensar alternativo con respecto a absolutos de hoy: subjetivismo, privilegiar el placer, héroes sagrados, progreso y éxito (de carácter discriminatorio), concebidos como meta de la humanidad.

Concluyo con unas posibilidades temáticas. En zonas indigenas, y en todo el continente, la teología está animada por una estrategia recreadora. Como advierte Pablo Richard, "fiel a su metodología y espíritu original, debemos recrear la teología de liberación ${ }^{\text {mz3 }}$. Es decir, afinar, retomar y, principalmente, recrear. Contamos con espiritualidad y con metodologías, y desde estas plataformas generamos una reflexión revitalizadora de los temas centrales en la teología cristiana.

Temótica fundamental. La condición humana actual y las tradiciones religiosas del mundo mayormente pobre nos abren las puertas a una consideración del evangelio y de la fe, del pecado y de la gracia. La cosmovisión indigena contribuye en especial a una eco-teología

Pensar a Dios según una revelación biblica carrelacionada con la sabiduría

Digitalizado por Biblioteca "P. Florentino Idoate, S.J."

Universidad Centroamericana José Simeón Cañas 
pequeña ( $f f$. Lc 10, 21). Hablar del misterio manifestado en la cotidianeidad del pueblo de Dios, y con la racionalidad moderna reformulada por los marginados.

Temática espirisual y festiva. La teología de la liberación, aunque la caricaturicen como reducción a lo político, es claro fruto de una espiritualidad sufriente y gozosa. Sus raíces indígenas, negras, mestizas, y la perspectiva de la mujer, son puntos de vista que imprimen mística y alegría a los conceptos teológicos.

Reflexión sacramental y litúr gica. Definen el ser cab́lico, con su pluralismo de signos comunitarios de la fe. La teología de la liberación es transformada por la creatividad ritual y simbólica del pobre que conlleva un modo de pensar.

Temática ética. Traduce el mandato del amor a los complejos desalíos de la acción: en el ámbito interpersonal, en el trabajo y la economía, y en cada responsabilidad humana. No es obnubilada por el subjetivismo ni por el relativismo de la moral secular. Retoma el ethos autóctono de reciprocidad y de sanación.

Eclesiología con un sentido inculturado y liberador, con un sentido de "unidad verificada en la diversidad" (Juan Pablo II, 1989), "con jerarquía y organización autóctonas, con teología, liturgia y expresiones eclesiales' ${ }^{124}$, que localmente verifican la unidad en el Espíritu del Señor. Visualizamos no una Iglesia dirigida a su auto-exaltación, sino hacia el reino, cuyos signos de los tiempos suscitan un pensar eclesial al servicio del reinado de Dios.

Estas y otras temáticas son trabajadas a la luz de la fe. Son luces pequeñas y penetrantes. En el caso de las comunidades andinas, ellas hacen teología y, a su modo, "encienden una lámpara... para que los que entran vean la luz" (Lc 8, 16; 11,33 ). Muchos gozan y piensan gracias a este resplandor. Uno agradece in [initamente poder descubrir la luz que hay en uno mismo, porque la lámpara alumbra a todos los que están en la casa ( $c f$. Lc 11, 35 y Mt 5, 15-16). A Dios nadie le ha visto. Por eso la teología sólo pucde ser como una cálida vela en medio de la oscuridad.

\section{Notas}

1. Los aproximadamente dos millones de aymaras están más de la mitad en comunidades campesinas, y menos de la mitad en márgenes de ciudades bolivianas y peruanas (y umos $\mathbf{4 0}$ mil en el norte de Chile). La mayoría está en el Altiplano, y algunos en serranías, selva y costa. Estos y otros rasgos permiten distinguir experiencias humanas y también teologías. Sin embargo, voy a recalcar lo aymara-en-común y lo compartido con la vecindad quechua y con mundos mestizos, lodo lo cual conforma "lo andino".

2. La analogía es trabajada por diversas disciplinas: filosolía teoría-científica de modelos, teología. Ver David Bumel, Analogy and philosophical language, N. Haven: Yale, 1973; David Tracy, The Analogical Imagination. N. York: Crossroad, 1981; y artículos de G. Sohngen en Mysterium Salutis, vol. 1, Madrid: Cristiandad, 1974, pp. 996-1011; y de L. Scheffczyk y J. Splett en Sacramensum Mundi, vol. 1, Barcelona: 
Herder, 1982, pp. 138-152. Teológicamente la relación de semejanza entre el ser humano (imagen de Dios) con Dios, nos mueve a poner nombres a Dios. "Hablamos de una sabiduria de Dios, misteriosa" (1Cor 2, 7). Hablamos de Dios mediante elementos semejantes y distintos del ser humano y el mundo. Como anota D. Tracy, los lenguajes teológicos suelen ser analógicos (afirmativos) o dialécticos (acento negativo, en "lcologías de la palabra"). En cuanto a la teología aymara, no es prelógica, ni sólo simbólica; principalmente es analógica.

3. Esta cosmovisión es como madeja de hilo que va envolviendo todo, tanto en époces pretéritas como en la actualidad. Hago referencia a Pachacuti Yamqui, Relación de Antiquedades deste Reyno del Perú, B.A.E. N²09, Madrid, 1968, pp. 291 (con la anotación del extirpador F. de Avila); y la interpretación de Tom Zuidema, Reyes y Guerreros, Lima: Fomciencias, 1989, pp. 38, 43, 90. Cito a comuneros quechuas de Pinchimuro, en B. Condori y R. Gow, Kaypacha, Cusco: Las Casas, 1982, pp. 11 y 97; y a la historia del cargador cusqueño, Gregorio Condori Mamani, Aurobiografta, Cusco: Las Casas, 1977, p. 50.

4. Exuraigo un trozo de la excelente compilación de 333 cantos quechuas a lo largo del Perú, por R. E. L. Montoya, La sangre de los cerros, Lima: CEPES, 1987, pp. 288. 289. Cito a T. Turino "The coherence of social style and musical creation among the aymara", Ethnomusicology, 1989, pp. 1-30, y a V. Cereceda, "Aproximaciones a una estética andina", en X. Albó (comp.), Mundo Aymara, Madrid: Alianza, 1988, pp. 347-352.

5. Canción de Regina Puma (reproducida en X. Alb6, obra cirada, p. 357): y un testimonio de Ana María Condori, Navan Uñatatawi, La Paz: Hisbo/Tahipanu, 1988, pp. 109, 186, 156-7.

6. Resaltan trabajos de H. van den Berg, La tierra no da asi no más. La Paz: Hisbol/ Úcb-Isen 1996, donde presenta lo ritual como tecnología simb6lica, cuyo transfondo es la visión de equilibrio en el universo y la tensión con fuerzas anti-nómicas en la naturajeza. sociedad y seres sagrados, y su acucioso Diccionario religioso aymara, Iquitos: Ceta e Idea, 1985; desde 1974 a 1979 en el Boletín del Instisuso de Estudios Aymaras (Chucuito), Víctor Ochoa ha detallado las ceremonias aymaras.

7. Xavier Alb6, “La experiencia religiosa aymara", en Los rosiros indios de Dios, Abya-Yala, 1991, en especial pp. 210-246.

8. Relato de Francisco Paz, de Qasani (Puno) "Titiqaq quta uñstawipata", recopilado por Ricardo Laura en 1988.

9. Canción recopilada por los hermanos Montoys, o. c., pp. 514-517.

0 . Fragmentos de un "credo aymara", elaborado durante un cursillo en Carabueo (Bolivia); publicado en Fe y Pueblo 18 (1987), p. 27.

1. Ver J. C. Scannone, "Mestizaje cultural y bautismo cultural" Stromala, 1/2 (1974), pp. 169-224; otra perspectiva es la de P. Trigo y G. Gutiérrez al analizar novelas latinoamericanas (y su mestizaje).

2. Varios Autores, Culiura negra y teologla, San José: DEI, 1986; Antonio da Silva, "Desafios teológicos pastorales a partir de la causa de los afro-brasileros" en Iglesia, Pueblos, Culiuras, vol. 4, Quito: Abya-Yala, 1987; M. Schuller, "Mulheres negras, uma nova dimençao teológica", Tempo e Preserça, 227 (1988), pp. 21-22; W. Amado, "Teología negra", Estudos, 1/2 (1988, pp. 63-79.

?. Porluncias en un encuentro de 1985, en Varios Autores, El rosiro femenino de la teología. San José: DEI, 1986; y en I. Gebara y M. C. Bingemer, A Mulher faz 
teologia, Petrópolis: Vozes, 1986; VV. AA., Vinieron unas mujeres, Montevideo: Obsur, 1989.

14. Síntesis en Mysterium Liberationis, Madrid: Trouth, 2 vols., 1990; L. y C. Boff. Como fazer teología da libertaçoe, Petrópolis: Vozes 1986, y C. Boff, Teología e pratica, Vozes, 1978; en cuanto a otras latitudes, D. Ferm, Third World Liberation Theologies, Marykonoll: Otbis, 1986. Resalta la sintonía entre teologías africanas, asiáticas e indoamericanas, todas alimentadas por vastas herencias culturales y por el af́́n de liberación del pobre (como indica el teólogo de Shri Lanka, A. Pieris "ineulturación y liberación, bien entendidas, son dos nombres para el mismo proceso". en VV. AA. Liberation in Asia, Delhi, 1987, p. 18).

15. Las teologlas de hoy son clasificadas de varias maneras; D. Tracy (Blessed rage for order, N. York: Seabury, 1975, pp. 22-42) las ordena según sus referencias a sujetos y objetos. Hoy predominan posturas neo-ortodoxas, y como advierte R. MeBrien (Catholicism, Minn. Winston Press, 1980, pp. 56-60) la tendencia orlodoxa est6́ limitada a fuentes generadas por la Iglesia.

16. Bemard Lonergan, Method in Theology, New York: Seabury, 1979, p. xi.

17. Hay una creciente elaboración ecuménica; menciono eventos donde he constatado grandes avances metodológicus. Consulta de Quito (1986) publicada como Aporte de los pueblos indígenas de América Latina a la teología cristiana., Quilo: AbyaYala, 1986. Taller del CTP sobre "religión aymara liberadora", publicado en $F e y$ Pueblo, 18 1987; Encuentro panandino de "teologfa andina" en Chucuito, 1990, (en proceso de publicación); Encuentro Latinoamericano, Teologia India, Quito: AbyaYala, 1991.

18. Aportes profesionales de X. Alb6, "Aprendamos a escuchar", Fe y Pueblo, 18 (19. 87), pp. 43-51, y su ya citada "Experiencia..."; Domingo Llarque, La cultura Ayma. ra. Lima: Tarea e Idea, 1990, pp. 41-172, y "Los ritos y creencias aymaras" (1990, ponencia en Chucuito, 1990); Enrique Jordá, "La cosmovisión aymara" en el diálogo de la fe, Lima, 1981, y "Tecnología en un contexto andino", Boletín del Instifuto de Estudios Aymaras, 20 (1985), pp. 49-57; obras ya citadas de H. van den Berg; y, de mi parte, un primet ensayo "Ingredientes y retos en la teología aymara", $F e$ y Pueblo, 18 (1987), pp. 31-37.

19. Me refiero a C. Siller, Para comprender el mensaje de Marla de Guadalupe. $\mathbf{B}$. Aires: Guadalupe, 1989; A. Wagua, "Algunos elementos para una catequesis kuna, apuntes teologicos kuna", Ustapa; 1990; P. Suess, "Mediaciones metodológicas de la teología cristiana" (1990), y "La nueva evangelización y la causa indigena", Boletín del Instituso de Estudios Aymaras, 34 (1990), pp. 77-91; B. Melia, "La experiencia religiosa guaran "en Rostros indios de Dios, pp. 268-317.

20. Comisión Episcopal para Indigenas, Fundamentos teologicos, de la pastoral indígena en México, México, 1988, pp. 95. Este documento es precursor de mucho que luego se irá elaborando en el continente.

21. Consulta de Quilo (1986), Aporie..., p. 50.

22. Este discemimiento fue iniciado en un taller sobre "Dios liberador y tierra" (1982), en que participarnos diecinueve agentes pastorales de la Prelatura de Juli (Perú).

23. P. Richard, "La teología de liberación en la nueva coyuntura", Pasos, 34 (1991), pp. 1-8. Según Ríchard, es una recreación en tres niveles: en las raíces (teología india, de la mujer, negra, de las culturas), a nivel de las CEB's y a nivel profesional

24. Departamento de Misiones del CELAM. Opciones Pasiorales, 1985, sección П/8, que posnla "Iglesias particulares indigenas" con las caracteristicas ya citadas.

Digitalizado por Biblioteca "P. Florentino Idoate, S.J."

Universidad Centroamericana José Simeón Cañas 